\title{
Effects of gonadotropin-releasing hormone agonist treatment on final adult height in boys with idiopa- thic central precocious puberty
}

\author{
Ah Young $\mathrm{Cho}^{1, *}$, \\ Su Yeong $\mathrm{Ko}^{2}$, \\ Jae Hee Lee ${ }^{3}$, \\ Eun Young Kim ${ }^{1}$
}

'Department of Pediatrics, Chosun University Hospital, Gwangju, Korea ${ }^{2}$ I-Mom Children \& Adolescent's Hospital, Gwangju, Korea

${ }^{3}$ Department of Pediatrics, Chungbuk National University Hospital, Chungju, Korea
Received: 2 December, 2020

Revised: 11 February, 2021

Accepted: 23 February, 2021

Address for correspondence:

Eun Young Kim

Department of Pediatrics, Chosun University Hostpital, 365 Pilmundaero, Dong-gu, Gwangju 61453, Korea

Email:sskey@chosun.ac.kr https://orcid.org/0000-0002-30735222

${ }^{*}$ Current affiliation: Department of Pediatrics, Ajou University School Medicine, Suwon, Korea
Purpose: There are few reports on the therapeutic effects of gonadotropin-releasing hormone agonists in boys with central precocious puberty, and studies reported in Korea are very rare. We aimed to assess the significance of clinical factors and the effects of gonadotropin-releasing hormone agonist treatment on final adult height in boys diagnosed with central precocious puberty.

Methods: We retrospectively evaluated the medical records of 18 boys treated for idiopathic central precocious puberty between 2007 and 2018 at Chosun University Hospital. Gestational age, birth weight, and parental height were assessed at the initial visit. Chronological age, bone age, bone age/chronological age ratio, height and height standard deviation scores, predicted adult height, body mass index, and hormone levels were assessed during the treatment period.

Results: At the time of diagnosis, the chronological age was $9.9 \pm 0.6$ years, the bone age was $11.6 \pm 1.0$ years, and the bone age/chronological age ratio was $1.20 \pm 0.1$. The bone age/chronological age ratio decreased significantly to $1.12 \pm 0.1$ at the end of treatment $(P<0.05)$. The luteinizing hormone/follicular stimulating hormone ratios were $3.4 \pm 1.2,0.6 \pm 0.4$, and $0.6 \pm 1.0$ at the start of treatment, after 1 year of treatment, and at the end of treatment, respectively. After gonadotropin-releasing hormone agonist treatment, the final adult height reached $172.0 \pm 4.8 \mathrm{~cm}$ compared to the target height range of $171.0 \pm 4.0 \mathrm{~cm}$.

Conclusion: In boys with central precocious puberty, gonadotropin-releasing hormone agonist treatment improved growth potential.

Keywords: Precocious puberty, Gonadotropin-releasing hormone, Boys

\section{Highlights}

GnRHa is a standard treatment for central precocious puberty in both boys and girls but, there are few reports on the effects of GnRHa in boys with central precocious puberty. So, this study aimed to analyze the significance of clinical factors and their effects on final adult height following GnRHa treatment diagnosed with central precocious puberty.

\section{Introduction}

The incidence of precocious puberty has recently increased along with the accelerated onset of puberty. ${ }^{1)}$ Central precocious puberty refers to conditions where activation of the hypothalamic-pituitary-gonadal axis leads to breast and testicular development before age 8 years in girls and 9 years in boys. ${ }^{2}$ Although the prevalence of central precocious puberty in boys is approximately 10 to 15 times lower than that in girls, ${ }^{3,4)}$ the incidence of central precocious puberty caused by organic conditions of the central nervous system is much higher 
in boys ( $40 \%$ to $90 \%$ ) than in girls (only $8 \%$ to $33 \%$ ). Therefore, brain magnetic resonance imaging (MRI) must be performed in boys with central precocious puberty to exclude organic causes. $^{5,6)}$

Early puberty accelerates growth and promotes bone maturation, resulting in early fusion that causes a decrease in final adult height (FAH). ${ }^{7-9)}$ Therefore, gonadotropin-releasing hormone agonists ( $\mathrm{GnRHa}$ ) are prescribed for children diagnosed with central precocious puberty to suppress the secretion of sex hormones, inhibit bone maturation, and improve FAH. ${ }^{7,8)}$

While there have been several studies on the effects of GnRHa treatment on clinical factors and FAH in girls with central precocious puberty, studies on the effects of long-term GnRHa treatment and FAH in boys with central precocious puberty are scarce, and studies reported in Korea are very rare. Therefore, the purpose of this study was to analyze the significance of clinical factors and their effects on FAH following GnRHa treatment in boys diagnosed with central precocious puberty.

\section{Materials and methods}

\section{Study design and patients}

This was a retrospective study of 18 boys diagnosed with and treated for central precocious puberty at the Department of Pediatrics of Chosun University Hospital between January
2007 and December 2018 and whose FAH could be assessed. Gestational age, birth weight, and parental height were assessed at the initial visit. Chronological age (CA), bone age (BA), BA/ CA ratio, height, body mass index (BMI), height standard deviation score (SDS), BMI SDS, predicted adult height (PAH), PAH SDS, luteinizing hormone (LH) level, follicle-stimulating hormone (FSH) level, LH/FSH ratio, and testosterone level were measured at three time points: the start of GnRHa treatment, after 1 year of treatment, and at the end of treatment.

The diagnostic criteria of central precocious puberty were (1) testicular volume of $4 \mathrm{~mL}$ or more before age 9 years and (2) peak LH level of $5 \mathrm{mIU} / \mathrm{mL}$ or more in the GnRH stimulation test. Patients with congenital adrenal hyperplasia and gonadal tumors were excluded from this study as these conditions can cause hypersecretion of male hormones. Brain MRI was performed to rule out central nervous system tumors. We excluded 6 children in whom an underlying organic brain lesion was found in brain MRI (microadenoma $n=4$. Rathke's cyst $n=1$, harmatoma $\mathrm{n}=1$ ).

\section{Measurements}

BA was measured using the Greulich-Pyle method by taking simple radiographs of the left hand and wrist. ${ }^{10)}$ Testicular volume was measured using a Prader orchidometer. Target height $(\mathrm{TH})$ was defined as the midparental height, which was calculated by adding $6.5 \mathrm{~cm}$ to the average parental height.

Table 1. Clinical and auxological characteristics of subjects

\begin{tabular}{|c|c|c|c|c|}
\hline Characteristic & At start of GnRHa & At 1 year after treatment & At end of treatment & At adult height \\
\hline CA (yr) & $9.9 \pm 0.6$ & $10.9 \pm 0.6^{*}$ & $11.8 \pm 0.5^{*, t}$ & $15.5 \pm 1.5^{*,+, \neq}$ \\
\hline$B A(y r)$ & $11.6 \pm 1.0$ & $12.4 \pm 1.2^{*}$ & $13.4 \pm 0.5^{*,+}$ & - \\
\hline $\mathrm{BA}-\mathrm{CA}$ & $1.72 \pm 0.7$ & $1.55 \pm 0.9$ & $1.52 \pm 0.9$ & \\
\hline $\mathrm{BA} / \mathrm{CA}$ & $1.20 \pm 0.1$ & $1.14 \pm 0.1$ & $1.12 \pm 0.1^{*}$ & - \\
\hline Height (cm) & $141.7 \pm 7.2$ & $147.9 \pm 7.2$ & $152.4 \pm 5.8^{*, t}$ & $172.0 \pm 4.8^{*, \dagger}$ \\
\hline Height SDS & $0.89 \pm 0.9$ & $0.87 \pm 0.8$ & $0.68 \pm 1.0^{*,+}$ & $0.39 \pm 1.0^{*, t, \pm}$ \\
\hline $\mathrm{PAH}(\mathrm{cm})$ & $172.7 \pm 5.7$ & $174.0 \pm 5.1$ & $172.8 \pm 4.9$ & - \\
\hline PAHSDS & $-0.13 \pm 1.3$ & $0.11 \pm 0.9$ & $-0.09 \pm 0.9$ & \\
\hline PAHa (cm) & $179.6 \pm 6.2$ & $180.2 \pm 5.6$ & $178.1 \pm 5.0$ & - \\
\hline PAHa SDS & $1.10 \pm 1.1$ & $1.21 \pm 0.9$ & $0.84 \pm 0.9$ & \\
\hline FAH-PAH (cm) & $-0.95 \pm 5.2$ & $2.28 \pm 4.2$ & $-1.13 \pm 3.4$ & \\
\hline FAH-PAHa (cm) & $-7.92 \pm 5.8$ & $-8.53 \pm 4.8$ & $-6.43 \pm 3.4$ & \\
\hline BMI $\left(\mathrm{kg} / \mathrm{m}^{2}\right)$ & $19.8 \pm 2.5$ & $20.4 \pm 2.7$ & $21.2 \pm 2.3^{*}$ & $21.9 \pm 3.0^{*,+}$ \\
\hline BMI SDS & $0.56 \pm 0.7$ & $0.50 \pm 0.7$ & $0.57 \pm 0.6$ & $0.22 \pm 0.8^{\ddagger}$ \\
\hline $\mathrm{LH}(\mathrm{mlU} / \mathrm{mL})$ & $16.6 \pm 4.3$ & $0.3 \pm 0.2^{*}$ & $0.3 \pm 0.2^{*}$ & $3.8 \pm 1.6^{*, t, \pm}$ \\
\hline $\mathrm{FSH}(\mathrm{mlU} / \mathrm{mL})$ & $6.1 \pm 2.2$ & $0.5 \pm 0.3^{*}$ & $0.6 \pm 0.3^{*}$ & $4.6 \pm 2.5^{*,+, \pm}$ \\
\hline LH/FSH & $3.4 \pm 1.2$ & $0.6 \pm 0.4^{*}$ & $0.6 \pm 1.0^{*}$ & $1.0 \pm 0.7^{*}$ \\
\hline Testosterone (ng/mL) & $3.2 \pm 5.6$ & $0.9 \pm 0.1^{*}$ & $0.1 \pm 0.1^{*}$ & $3.4 \pm 0.9^{t, \pm}$ \\
\hline Duration of GnRHa (mo) & - & - & $23.6 \pm 9.1$ & - \\
\hline $\mathrm{TH}(\mathrm{cm})$ & $171.0 \pm 4.0$ & - & - & - \\
\hline
\end{tabular}

Values are presented as mean \pm standard deviation.

$\mathrm{GnRHa}$, gonadotropin-releasing hormone agonist; CA, chronological age; BA, bone age; PAH, predicted adult height-calculated with average table of Baley-Pinneau (BP) method; SDS, standard deviation score; PAHa, predicted adult height-calculated with advanced; FAH, final adult height; BMI, body mass index; LH, luteinizing hormone; FSH, follicular stimulating hormone; TH, target height.

${ }^{*} P<0.001$ compared with start of treatment. ${ }^{\dagger} P<0.001$ compared with 1 year after treatment. ${ }^{\ddagger} P<0.001$ compared with end of treatment. 
Bayley-Pinneau (BP) average tables and BP-advanced tables were used to measure PAH and PAHa, respectively. ${ }^{11)} \mathrm{FAH}$ was defined as the height measured when $\mathrm{BA} \geq 16$ years and growth rate $<1 \mathrm{~cm} / \mathrm{yr}$. The standard growth chart for children and adolescents published by the Korean Pediatrics Association in 2017 was used. $^{12)}$

\section{Statistical analysis}

The results were expressed as the mean value \pm standard deviation, and a Friedman test was performed to evaluate the significance of the difference in the mean value of the clinical factors according to the treatment period of all 18 children. Spearman correlations analysis was performed to assess the relationship between the FAH and PAH assessed using the average and advanced tables of the BP method during the treatment period. For factors that can affect FAH, simple linear regression and multiple linear regression with stepwise variable selection were used. All statistical analyses were performed using IBM SPSS Statistics ver. 24.0 (IBM Co., Armonk, NY, USA).

\section{Results}

\section{Patient characteristics}

Clinical factors according to the period of GnRHa treatment in a total of 18 boys are shown in Table 1. The CA and BA at the start of GnRHa treatment were $9.9 \pm 0.6$ years and $11.6 \pm 1.0$ years, respectively. After 1 year of treatment, the CA was $10.9+0.6$ years, and the BA was $12.4 \pm 1.2$ years. At the end of treatment, the CA and BA were $11.8 \pm 0.5$ years and $13.4 \pm 0.5$ years, respectively. The BA/CA ratios were $1.20 \pm 0.1,1.14 \pm 0.1$, and $1.12 \pm 0.1$ at the start of treatment, after 1 year of treatment, and at the end of treatment, respectively. BA/CA ratio reduction was statistically significant at diagnosis and the end of treatment $(P<0.05)$, suggesting that bone maturation was inhibited by GnRHa treatment. The BA-CA difference decreased during the treatment period, but there was no statistical significance. The mean duration of GnRHa treatment was $23.6 \pm 9.1$ months.

The TH of all 18 children was $171.0 \pm 4.0 \mathrm{~cm}$, and the FAH after GnRHa treatment was $172.0 \pm 4.8 \mathrm{~cm}$. The $\mathrm{LH} / \mathrm{FSH}$ ratio
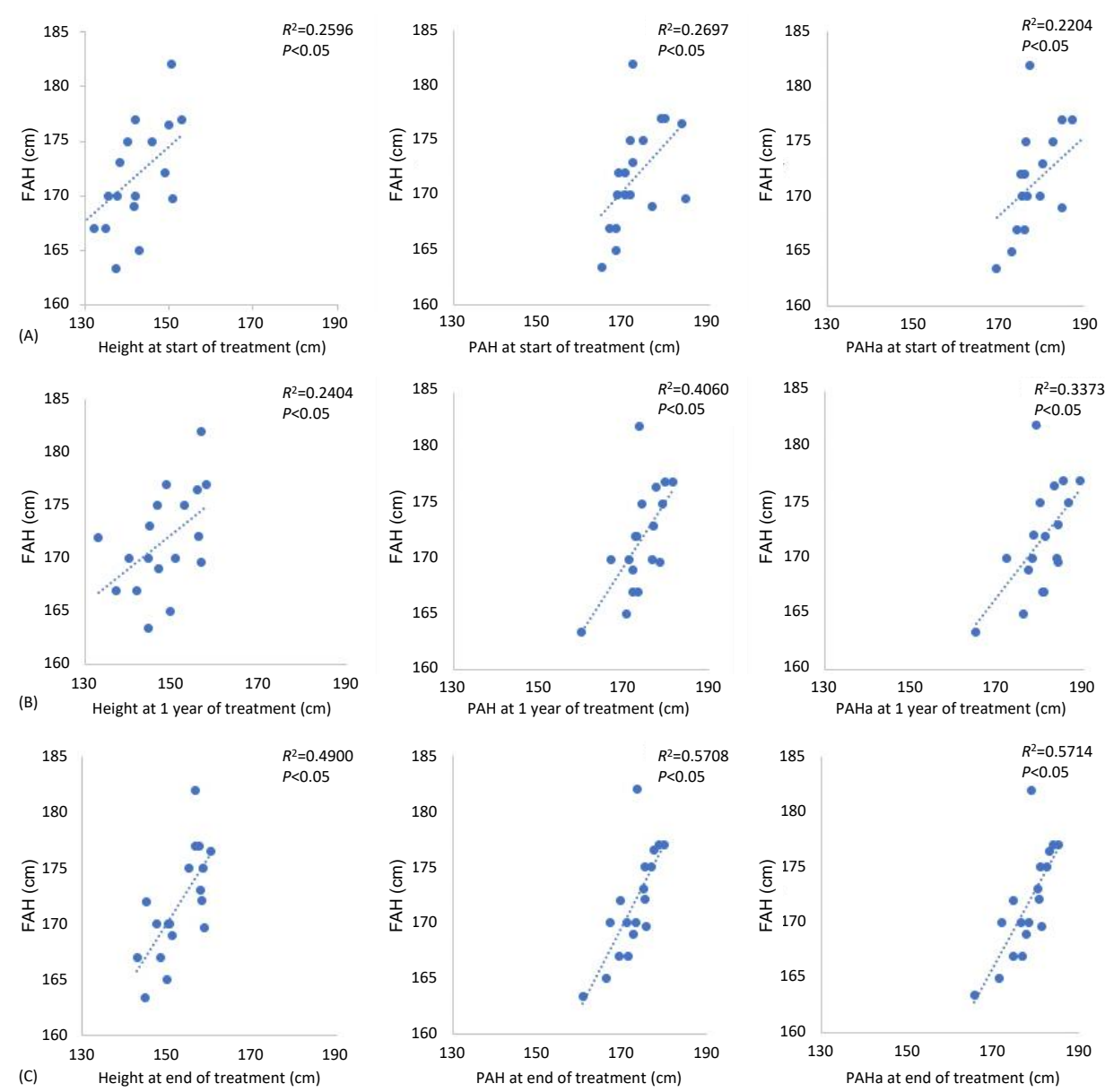

Fig. 1. Correlation between FAH and height, PAH, PAHa during treatment period. At start of treatment (A), 1 year after treatment (B), and end of treatment (C). FAH, final adult height; PAH, predicted adult height-calculated with average table of Baley-Pinneau (BP) method; PAHa, predicted adult height-calculated with advanced table of BP method. 
at the time of diagnosis was 3.4 \pm 1.2 , and it was significantly decreased to $0.6 \pm 0.4$ and $0.6 \pm 1.0$ after 1 year of treatment and at the end of treatment, respectively $(P<0.05)$. The testosterone level at the time of diagnosis was $3.2 \pm 5.6 \mathrm{ng} / \mathrm{mL}$, and it significantly decreased to $0.9 \pm 0.1 \mathrm{ng} / \mathrm{mL}$ after 1 year of treatment $(P<0.05)$.

\section{Relationship of $\mathrm{PAH}, \mathrm{PAHa}$, and $\mathrm{FH}$ according to treatment period}

The correlation between FAH and height, PAH, PAHa according to treatment period is shown in Fig. 1. At the start of GnRHa treatment (Fig. 1A), the FAH correlated with height $\left(R^{2}=0.2596, P<0.05\right)$, PAH $\left(R^{2}=0.2697, P<0.05\right)$, PAHa $\left(R^{2}=0.2204, P<0.05\right)$. Similarly, at 1 year after treatment (Fig. $1 B)$ and at end of treatment (Fig. 1C), the FAH correlated with height $\left(R^{2}=0.2404, P<0.05\right)$, PAH $\left(R^{2}=0.4060, P<0.05\right)$, PAHa $\left(R^{2}=0.3373, P<0.05\right)$ and $\left(R^{2}=0.4900, P<0.05\right)$, PAH $\left(R^{2}=0.5708\right.$, $P<0.05)$, PAHa $\left(R^{2}=0.5714, P<0.05\right)$, respectively. During the treatment period, a significant correlation was found between FAH and height, PAH, and PAHa. At the end of treatment, $\mathrm{PAH}$ and PAHa showed a high correlation with FAH.

At the start of GnRHa treatment, the PAH and PAHa were $172.7 \pm 5.7 \mathrm{~cm}$ and $179.6 \pm 6.2 \mathrm{~cm}$, respectively, which were higher than the mean TH of $171.0 \pm 4.0 \mathrm{~cm}$. PAH and PAHa after 1 year of treatment were increased relative to that at the start of treatment to $174.0 \pm 5.1 \mathrm{~cm}$ and $180.2 \pm 5.6 \mathrm{~cm}$, respectively. At the end of treatment, PAH was $172.8 \pm 4.9 \mathrm{~cm}$ and PAHa was $178.1 \pm 5.0 \mathrm{~cm}$. The FAH was $172.0 \pm 4.8 \mathrm{~cm}$, which was within the $\mathrm{TH}$ of $171.0 \pm 4.0 \mathrm{~cm}$.

\section{Clinical factors influencing FAH}

We performed a simple linear regression analysis on the factors that influence the FAH (Table 2). At the start of GnRHa treatment, TH, height, height SDS, PAH, and PAHa were positively correlated with FAH $(\beta=0.656,0.512,0.631,0.519$, $0.524,0.469$, and 0.474 , respectively; all $P<0.05)$. After 1 year of treatment, height, height SDS, $\mathrm{PAH}$, and PAHa remained significant influencing factors $(\beta=0.490,0.627,0.638,0.637$, $0.581,0.581$, respectively; all $P<0.05)$. At the end of treatment, height, height SDS, PAH, SDS of PAH, PAHa, and PAHa SDS had significant positive correlations with FAH $(\beta=0.700$, $0.585,0.756,0.755,0.756$, and 0.755 , respectively; all $P<0.05$ ). In multiple linear regression analysis using stepwise variable selection based on factors that were significantly correlated with the FAH during the treatment period, only PAHa at the end of treatment was found to be significantly correlated with the FAH $\left(R^{2}=0.571, P<0.05\right)($ Table 3$)$.

\section{Discussion}

In this study, we analyzed the effect of GnRHa treatment on FAH in boys diagnosed with central precocious puberty. Precocious puberty caused by organic conditions is more

Table 3. Multiple regression analysis of factors influencing final adult height in $\mathrm{GnRHa}$ treated boys $\left(\mathrm{n}=18, R^{2}=0.571\right)$

\begin{tabular}{lccc}
\hline Variable & Coefficient $(\beta)$ & SE & $P$-value \\
\hline PAHa at end of treatment & 0.756 & 0.155 & $<0.001$ \\
\hline
\end{tabular}

Stepwise multiple linear regression of the following independent variables: Height (at start of treatment, 1 year after treatment, end of treatment), PAH (at start of treatment, 1 year after treatment, end of treatment), PAHa (at start of treatment, 1 year after treatment, end of treatment).

$\mathrm{SE}$, standard error; PAH, predicted adult height-calculated with average table of Baley-Pinneau (BP) method; $\mathrm{PAHa}$, predicted adult height-calculated with advanced table of BP method.

Table 2. Factors influencing final adult height in GnRHa treated boys at GnRHa treatment

\begin{tabular}{|c|c|c|c|c|c|c|}
\hline \multirow{2}{*}{ Variable } & \multicolumn{2}{|c|}{ At GnRHa treatment } & \multicolumn{2}{|c|}{ At 1 year after treatment } & \multicolumn{2}{|c|}{ At end of treatment } \\
\hline & Coefficient $(\beta)$ & $P$-value & Coefficient $(\beta)$ & $P$-value & Coefficient ( $\beta$ ) & $P$-value \\
\hline $\mathrm{TH}(\mathrm{cm})$ & 0.656 & $<0.05$ & - & - & - & - \\
\hline CA (yr) & 0.035 & 0.889 & -0.082 & 0.747 & 0.08 & 0.753 \\
\hline BA (yr) & 0.035 & 0.459 & 0.049 & 0.847 & 0.155 & 0.539 \\
\hline $\mathrm{BA} / \mathrm{CA}$ & 0.247 & 0.323 & 0.138 & 0.585 & 0.145 & 0.567 \\
\hline $\mathrm{BA}-\mathrm{CA}$ & 0.245 & 0.328 & 0.123 & 0.627 & 0.141 & 0.576 \\
\hline Height & 0.512 & $<0.05$ & 0.490 & $<0.05$ & 0.700 & $<0.05$ \\
\hline Height SDS & 0.631 & $<0.05$ & 0.627 & $<0.05$ & 0.585 & $<0.05$ \\
\hline $\mathrm{PAH}(\mathrm{cm})$ & 0.519 & $<0.05$ & 0.638 & $<0.05$ & 0.756 & $<0.05$ \\
\hline PAHSDS & 0.524 & $<0.05$ & 0.637 & $<0.05$ & 0.755 & $<0.05$ \\
\hline PAHa $(\mathrm{cm})$ & 0.469 & $<0.05$ & 0.581 & $<0.05$ & 0.756 & $<0.05$ \\
\hline PAHa SDS & 0.474 & $<0.05$ & 0.581 & $<0.05$ & 0.755 & $<0.05$ \\
\hline BMI (kg/m2) & -0.366 & 0.136 & -0.406 & 0.095 & 0.463 & 0.299 \\
\hline BMI SDS & -0.387 & 0.113 & -0.446 & 0.063 & 0.072 & 0.281 \\
\hline Duration of treatment & - & - & - & - & -0.043 & 0.866 \\
\hline
\end{tabular}

GnRHa, gonadotropin-releasing hormone agonist; TH, target height; CA, chronological age; BA, bone age; SDS, standard deviation score; $\mathrm{PAH}$, predicted adult height-calculated with average table of Baley-Pinneau (BP) method; PAHa, predicted adult height-calculated with advanced table of BP method; BMI, body mass index. 
frequent in boys than in girls, and the cause of central precocious puberty in boys must be identified. ${ }^{13)}$ The incidence of central precocious puberty in boys has increased over the past 10 years and has been reported to be associated with an increase in idiopathic precocious puberty. In a study of 100 boys with central precocious puberty from 2003 to $2014,74 \%$ had idiopathic disease, and the remaining $26 \%$ of cases were caused by organic conditions. Moreover, when the authors divided the cases into 2-year unit (i.e., 2003-2005, 2006-2008, 2009-2011, and 2012-2014), the proportion of children with idiopathic central precocious puberty was shown to be gradually increasing over time $(33.3 \%, 64.7 \%, 80.6 \%$, and $81.6 \%$, respectively). ${ }^{14)}$

GnRHa is a standard treatment for central precocious puberty in both boys and girls. It is known to suppress the secretion of sex hormones to slow puberty and suppress rapid bone fusion to achieve FAH within the TH range. ${ }^{15,16)}$ However, there have been fewer studies on the effects of long-term GnRHa treatment in boys with central precocious puberty than in girls. Existing studies published abroad also had a limited sample size. Moreover, there are very rare studies in Korea on the effects of GnRH treatment on clinical factors and FAH in boys with central precocious puberty. In a multicenter study conducted in Italy involving 45 boys with precocious puberty, 27 (60\%) had idiopathic disease and 18 children (40\%) had central nervous system lesions. Hamartoma was the most common central nervous system lesion, followed by neurofibromatosis (5 children), central nervous system malformation (5 children), and ependymoma (2 children). The basal LH level and the peak LH/FSH ratio were higher in children with organic lesions, but the difference was not significant. ${ }^{177}$ In a study of 22 girls and 11 boys with idiopathic central precocious puberty, both boys and girls showed a significant decrease in the BA/CA ratio during treatment, and PAH was increased. In girls, the PAH at the start of treatment was $155.2 \pm 4.7 \mathrm{~cm}$, and this significantly increased to $160.5 \pm 6.1 \mathrm{~cm}$ at the end of treatment. Similarly, the PAH was $168.3 \pm 2.12 \mathrm{~cm}$ in boys at the start of treatment and was significantly increased to $179.0 \pm 5.0 \mathrm{~cm}$ at the end of treatment. The FAH was $158.5 \pm 5.3 \mathrm{~cm}$ and $179.0 \pm 5.0 \mathrm{~cm}$ for girls and boys, respectively, which was significantly higher than the pretreatment PAH in both groups. ${ }^{18)}$

In a study of 12 boys with central precocious puberty published in Italy, the CA and BA at the time of diagnosis were 7.6 \pm 0.9 years and $10.9 \pm 1.7$ years, respectively. The TH was $174.2 \pm 2.9 \mathrm{~cm}$, and the PAH at the time of diagnosis was $169.9 \pm 4.2 \mathrm{~cm}$. During treatment, the PAH significantly increased to $180.7 \pm 6.0 \mathrm{~cm}$. Furthermore, the FAH was $176.1 \pm 6.1 \mathrm{~cm}$, which was increased as compared with $\mathrm{TH}$ and PAH at the time of diagnosis. Height SDS at the end of treatment was identified to be an influencing factor of $\mathrm{FAH} .{ }^{19)}$ In a study of 98 children with precocious puberty, the FAH of 18 boys was $171.1 \pm 8.7 \mathrm{~cm}$, which was significantly increased from the PAH of $156.1 \pm 14.2 \mathrm{~cm}$ at the time of diagnosis. ${ }^{20)}$ In the current study, the FAH was $172.0 \pm 4.8$ $\mathrm{cm}$, which was higher than the TH of $171.0 \pm 4.0 \mathrm{~cm}$. However, during the treatment period, $\mathrm{PAH}$ and PAHa were increased compared to the TH of $171.0 \pm 4.0 \mathrm{~cm}$. Considering that in boys, bone maturity appears in the latter half of sexual maturity compared with girls, there is a time difference before the increased sex hormone concentration at the time of diagnosis of precocious puberty is reflected in BA. Thus, it is thought that BA is less evolved at the time of diagnosis, which leads to exaggerated PAH and PAHa as assessed using the BP method. ${ }^{21.22)}$ Compared to previous studies showing that untreated patients might lose their growth potential up to $10 \mathrm{~cm},{ }^{18)}$ our study in boys with GnRHa treatment recovered growth potential beyond the range of TH. Previous studies showed that the influencing factors of FAH after GnRHa treatment in girls with central precocious puberty included young CA at the time of diagnosis, height SDS at the start and end of treatment, and duration of treatment. ${ }^{23-25}$ In our previous study of 69 girls diagnosed with and treated for central precocious puberty, the significant factors related to FAH were TH, height at the start of GnRHa treatment, height SDS, PAH, and height SDS at the end of treatment. ${ }^{26)}$ The few studies on the influencing factors of FAH following GnRHa treatment in boys identified TH and height at the end of GnRHa as important predictive factors. ${ }^{19)}$ In the current study, PAHa at the end of treatment was positively associated with FAH.

Interestingly, in our study, the level of FAH was similar to the PAH based on the BP method average table. It is well known in the literature that when predicting adult heights via the BP method, the prediction may overestimate $\mathrm{FAH}$ in pediatric patients with normal or advanced $\mathrm{BA}$ and $\mathrm{PAH}$, which does not greatly differ regardless of treatment, is more appropriate in predicting FAH in pediatric patients with CPP. Additionally, caution should be taken in predicting FAH in practice because the prediction using the BP method during GnRHa treatment or end of treatment overestimates FAH. ${ }^{27.28)}$ That is, in comparison to normal puberty, gonadotropin and sex hormone levels elevate more rapidly after treatment is complete, arriving at the maximum level sooner, and the children reach their FAH earlier. Hence, the FAH during treatment and afterwards may be smaller. ${ }^{29)}$ Likewise, in our study, the genetic potential to reach $\mathrm{TH}$ was recovered in FAH, but the height was found to be smaller than PAH and PAHa at the time of treatment completion and rather closer to the PAH based on the average table. However, in this study we identified PAHa at the end of treatment as a factor influencing FAH. Rather than interpreting the finding as showing a value close to actual FAH, we believe it more appropriate to interpret the factor as influencing growth to FAH by recovering growth potential after treatment to help increase FAH in the children.

As previously mentioned, there are few papers dealing with the treatment effect of GnRHa on clinical factors and FAH in Korean male CPP patients. In this respect, our study will be helpful in future clinical applications. However, this study was also conducted on a small number of subjects with a relatively short follow-up period. Therefore, long-term studies with a larger sample size are needed to validate our findings.

In conclusion, GnRHa treatment can help boys with precocious puberty reach $\mathrm{FAH}$ near the $\mathrm{TH}$ range. 


\section{Ethical statement}

This study was approved by the Institutional Review Board (IRB) of Chosun University Hospital (IRB No. 2020-04-006). This study was retrospective and was, therefore, exempted from need for informed consent.

\section{Conflict of interest}

No potential conflict of interest relevant to this article was reported.

\section{Funding}

This study was supported by a research fund received from Chosun University Hospital 2019.

\section{References}

1. Kim JH, Shin CH. Observed trends for an earlier onset of puberty: when is the need for treatment indicated. J Korean Med Assoc 2009;52:1189-200.

2. Mul D, Redriks AM, Van BS, Oostdijk W, VerlooveVanhorick SP, Wit JM. Pubertal development in the Netherlands 1965-1997. Pediatr Res 2001;50:479-86.

3. Teilmann G, Pedersen CB, Jensen TK, Skakkebaek NE, Juul A. Prevalence and incidence of precocious pubertal development in Denmark: an epidemiologic study based on national registries. Pediatrics 2005;116:1323-8.

4. Carel JC, Léger J. Clinical practice. Precocious puberty. N Engl J Med 2008;358:2366-77.

5. Carel JC, Lahlou N, Roger M, Chaussi JL. Precocious puberty and statural growth. Hum Reprod Update 2004;10:135-47.

6. Rhie YJ, Lee KH. Overview and treatment of precocious puberty. J Korean Med Assoc 2015;58:1138-44.

7. John SF. Treatment and outcomes of precocious puberty. J Clin Endocrinol Metab 2013;98:2198-207.

8. Bertelloni S, Baroncelli GI, Sorrentino MC, Perri G, Saggese G. Effect of central precocious puberty and gonadotropinreleasing hormone analogue treatment on peak bone mass and final height in females. Eur J Pediatr 1998;157:363-7.

9. Lahlou N, Carel JC, ChaussainJL, Roger M. Pharmacokinetics and pharmacodynamics of GnRH agonist: clinical implications in pediatrics. J Pediatr Endocrinol Metab 2000;13:723-37.

10. Greulich WW, Pyle SI. Radiographic atlas of skeletal development of the hand and wrist. 2nd ed. Standford (CA): Standford University Press, 1971.

11. Bayley N, Pinneau SR. Tables for predicting adult height from skeletal age: revised for use with the Greulich-Pyle hand standards. J Pediatr1952;40:423-41.

12. Kim JH, Yun SH, Hwang SS, Shim JO, Chae HW, Lee YJ, et al. The 2017 Korean national growth charts for children and adolescents: development, improvement, and prospects. Korean J Pediatr 2018;61:135-49.

13. Lee JS, Kim JS, Yang AR, Cho SY, Jin DK. Etiology trends in male central precocious puberty. Ann Pediatr Endocrinol Metab 2018:23:75-80.

14. Alikasifoglu A, Vuralli D, GoncEN, Ozon A, Kandemir N. Changing etiological trends in male precocious puberty: Evaluation of 100 cases with central precocious puberty over the last decade. Horm Res Paediatr 2015;83:340-44.

15. Rhie YJ, Lee KH. Overview and treatment of precocious puberty. J Korean Med Assoc 2015;58:1138-44.

16. Mul D, Oostdijk W, Otten BJ, Rouwé C, Jansen M, Delemarre-van de Waal HA, et al. Final height after gonadotrophin releasing hormone agonist treatment for central precocious puberty: the Dutch experience. J Pediatr Endocrinol Metab 2000;13 Suppl 1:765-72.

17. De Sanctis V, Corrias A, Rizzo V, Bertelloni S, Urso L, Galluzzi F, et al. Etiology of central precocious puberty in males: the results of the Italian Study Group for Physiopathology of Puberty. J Pediatr Endocrinol Metab 2000;13 Suppl 1:687-93.

18. Galluzzi F, Salti R, Bindi G, Paszuini E, La Cauza C. Adult height comparison between boys and girls with precocious puberty after long-term gonadotrophin-releasing hormone analogue therapy. Acta Paediatr 1998;87:521-7.

19. Rizzo V, De Sanctis V, Corrias A, Fortini M, Galluzzi F, Bertelloni S, et al. Factors influencing final/near-final height in 12 boys with central precocious puberty treated with gonadotrophin-releasing hormone agonists. Italian Study Group of Physiopathology of Puberty. J Pediatr Endocrinol Metab 2000;13 Suppl 1:781-6.

20. Klein KO, Barnes KM, Jones JV, Feuillan PP, Cutler GB Jr. Increased final height in precocious puberty after long term treatment with LHRH agonist: The National Institutes of Health experience. J Clin Endocrinol Metab 2001;86;47116.

21. Lazar L, Pertzelan A, Weintrob N, Phillip M, Kauli R. Sexual precocity in boys: accelerated versus slowly progressive puberty gonadotropin-suppressive therapy and final height. J Clin Endocrinol Metab 2001;86:4127-32.

22. Oostdijk W, Rikken B, Schreuder S, Otten B, Odink R, Rouwe $\mathrm{C}$, et al. Final height in central precocious puberty after long term treatment with a slow release $\mathrm{GnRH}$ agonist. Arch Dis Child 1996;75:292-7.

23. Heger S, Partsch CJ, Sippell WG. Long-term outcome after depot gonadotropin-releasing hormone agonist treatment of central precocious puberty: final height, body proportions, body composition, bone mineral density, and reproductive function. J Clin Endocrinol Metab 1999;84:4583-90.

24. Lee HS, Yoon JS, Park KJ, Hwang JS. Increased final adult height by gonadotropin releasing hormone agonist in girls with idiopathic central precocious puberty. PLoS One 2018;13:e0201906.

25. Guaraldi F, Beccuti G, Gori D, Ghizzoni L. Management of 
endocrine disease: long-term outcomes of the treatment of central precocious puberty. Eur J Endocrinol 2016;174:R7987.

26. Cho AY, Ko SY, Lee JH, Kim EY. Relationship between final adult height and birth weight after gonadotropin-releasing hormone agonist treatment in girls with central precocious puberty. Ann Pediatr Endocrinol Metab 2020;25:24-30.

27. Tarım O. Height predictions by Bayley-Pinneau method may misguide pediatric endocrinologists. Turk J Pediatr 2013;55:485-92.
28. Oerter KE, Manasco P, Barnes KM, Jones J, Hill S, Cutler GB Jr. Adult height in precocious puberty after longterm treatment with deslorelin. J Clin Endocrinol Metab 1991;73:1235-40.

29. Tanaka T, Niimi H, Matsuo N, Fujieda K, Tachibana K, Ohyama K, et al. Results of long-term follow-up after treatment of central precocious puberty with leuprorelin acetate: evaluation of effectiveness of treatment and recovery of gonadal function. The TAP-144-SR Japanese Study Group on Central Precocious Puberty. J Clin Endocrinol Metab 2005;90:1371-6. 